\title{
CONSCIENTIZAÇÃO AMBIENTAL DA POPULAÇÃO NA REGIÃO CENTRAL DA APA COSTA DOS CORAIS
}

Gildo Rafael de Almeida Santana ${ }^{1}$

Eliane Barbosa Santos ${ }^{2}$

Resumo: O presente trabalho tem como objetivo identificar e mensurar o grau de conscientização ambiental da população na região central da Área de Proteção Ambiental (APA) Costa dos Corais. Para tanto, foi aplicado um questionário nos municípios de Porto de Pedras-AL e São Miguel dos MilagresAL. Para mensurar o grau de conscientização ambiental, foi utilizado as escalas de Likert, onde requerem que os entrevistados indiquem seu grau de concordância ou discordância com declarações relativas à atitude que está sendo medida. Os resultados indicam que há traços de consciência ambiental na população dos municípios estudados. No entanto, ainda se faz necessário uma educação ambiental crítica, principalmente entre as crianças e jovens.

Palavras-chave: Alagoas; Educação Ambiental; Índice de Consciência Ambiental; Unidade de Conservação.

${ }^{1}$ Instituto Federal de Alagoas/Universidade Aberta do Brasil. E-mail: gildoraphael@gmail.com 2 Universidade Federal do Rio Grande do Norte. E-mail: elianbs@gmail.com. 


\section{Introdução}

A Área de Proteção Ambiental (APA) Costa dos Corais é a maior unidade de conservação federal marinha do Brasil, está localizado no Nordeste, litoral sul de Pernambuco (PE) e litoral norte de Alagoas ( $A L)$, entre os municípios de Tamandaré/PE e Maceió/AL. A presença de recifes de coral é a principal característica da região e, associados aos manguezais, formam o habitat para muitas espécies, inclusive de espécies ameaçadas de extinção, como o peixe boi marinho (Trichechus manatus). No entanto, lançamentos de resíduos nos recursos hídricos desta região tem gerado sérios problemas ambientais. Segundo o Instituto do Meio Ambiente de AL (IMA) o Rio Tatuamunha (Santuário do Peixe-Boi), situado na região central da APA Costa dos Corais, possui oscilações entre períodos considerados próprios e impróprios para o banho, onde de acordo com a Resolução 274/2000 do Conselho Nacional do Meio Ambiente (CONAMA), é considerada própria para o banho, quando em $80 \%$ ou mais de um conjunto de amostras obtidas em cada uma das cinco semanas anteriores, colhidas no mesmo local, não exceder um limite de 1.000 Coliformes Termotolerantes (Fecais) por $100 \mathrm{~mL}$ da amostra de água.

Nos recursos hídricos, a qualidade da água pode ser afetada por diversas atividades do homem, sejam elas domésticas, comerciais ou industriais. Cada uma dessas atividades gera poluentes característicos que têm um determinado efeito. Segundo Capelli (2007), os resíduos são um dos mais graves problemas ambientais de causa antrópica. Portanto, é necessária uma mudança de comportamento, sendo a educação ambiental condição necessária para que haja essa mudança. $O$ educador ambiental tem como função crítica, desenvolver nos indivíduos uma conscientização ambiental. Essa conscientização, pode ser entendida como a mudança de comportamento, tanto em atividades quanto em aspectos da vida, dos indivíduos e da sociedade em relação ao meio ambiente (BUTZKE et al., 2001). Segundo Sorrentino (1998), os grandes desafios para os educadores ambientais são, de um lado, o resgate e o desenvolvimento de valores e comportamentos (confiança, respeito mútuo, responsabilidade, compromisso, solidariedade e iniciativa) e de outro, o estímulo a uma visão global e crítica das questões ambientais e a promoção de um enfoque interdisciplinar que resgate e construa saberes.

Na região central da APA, entre Porto de Pedras-AL e São Miguel dos Milagres- $\mathrm{AL}$, onde está localizado o santuário do Peixe-Boi, a economia local vem crescendo devido à ampliação da cadeia do turismo, tendendo a incrementar problemas socioambientais, como poluição dos recursos hídricos e destinação inadequada de resíduos sólidos. Com a poluição e contaminação da água, várias espécies poderão ser afetadas, inclusive as espécies de peixes que servem de alimento ao homem. Neste sentido, entender o grau de conscientização ambiental da população nesta região, pode ser fundamental para a elaboração de estratégias e formas de atuação que contribuam para uma análise mais profunda dos problemas socioambientais, de forma que 
proporcione a emancipação dos sujeitos da ação. Diante do exposto, o objetivo deste estudo é identificar e mensurar o grau de conscientização ambiental nos municípios de Porto de Pedras-AL e São Miguel dos Milagres-AL.

\section{Metodologia}

Para a realização deste estudo, foi aplicado um questionário (Apêndice A) nos municípios de Porto de Pedras-AL e São Miguel dos Milagres-AL, contendo 15 questões. $O$ grau de conscientização ambiental foi mensurado analisando as questões de 1 a 10 , que estão relacionadas aos hábitos de consumo de água, energia e destinação do lixo. O perfil do entrevistado foi descrito nas questões de 11 a 15 , sendo analisados a idade, escolaridade, renda familiar, sexo e em qual município reside.

O questionário foi aplicado no mês de maio de 2014 nas principais escolas dos municípios de Porto de Pedras e São Miguel dos Milagres, colônia de pescadores Z-25, ONG's, Projeto Jovens Protagonista da Costa dos Corais e população em geral.

O método utilizado para mensurar o grau de conscientização ambiental, foram semelhantes aos utilizados por Bertolini e Possamai (2005) e Zaccari e Oliveira (2013), que utilizaram as escalas de Likert. As escalas de Likert, requerem que os entrevistados indiquem seu grau de concordância ou discordância com declarações relativas à atitude que está sendo medida. Atribui-se valores numéricos e/ou sinais às respostas para refletir a força e a direção da reação do entrevistado à declaração. As declarações de concordância devem receber valores positivos ou altos, enquanto as declarações das quais discordam devem receber valores negativos ou baixos (BAKER, 2005). Todas as questões do questionário foram elaboradas contendo quatro alternativas como resposta, onde foi atribuído peso a cada uma: sempre (4 pontos), algumas vezes (3 pontos), raramente (2 pontos) e nunca (1 ponto). Posteriormente, foi calculado o Índice de Consciência Ambiental (ICA) baseado na média aritmética das pontuações, obtido da seguinte forma:

$$
I C A=\frac{P_{Q 1}+P_{Q 2}+P_{Q 3}+P_{Q 4}+\cdots+P_{Q 10}}{10}
$$

onde $P_{Q}$ é a pontuação das questões de 1 a 10.

Esse índice, foi utilizado para mensurar o grau de conscientização ambiental, seguindo a classificação da Tabela 1. 
Tabela 1: Grau de conscientização ambiental.

\begin{tabular}{l|l}
\hline Classificação & Pontos \\
\hline Consciente em reação ao meio ambiente & $4-3,5$ \\
Potenciais traços de consciência ambiental & $3,5-2,5$ \\
Poucos traços de consciência ambiental & $2,5-1,5$ \\
Não possui consciência ambiental & $1,5-1$ \\
\hline
\end{tabular}

Fonte: Bertolini e Possamai (2005).

\section{Resultados e discussão}

$\mathrm{Na}$ Tabela 2, podemos observar o perfil dos entrevistados. No total foram 300 entrevistados, sendo 136 do município de Porto de Pedras, 123 do município de São Miguel dos Milagres e 31 de outros municípios (Japaratinga e Passo de Camaragibe). A faixa etária dos entrevistados está entre 14 e 50 anos e, $86,7 \%$ destes têm renda familiar até dois salários mínimos. Em relação a escolaridade, a maior parte (64\%) possui segundo grau incompleto e apenas $7,3 \%$ possui superior completo.

Tabela 2: Perfil dos entrevistados.

\begin{tabular}{|c|c|c|c|c|c|}
\hline \multicolumn{3}{|c|}{ Idade } & \multicolumn{3}{|c|}{ Renda familiar } \\
\hline & Frequência & $\%$ & & Frequência & $\%$ \\
\hline até 14 anos & 36 & 12.0 & $<1$ salário & 122 & 40.7 \\
\hline 15 a 24 anos & 226 & 75.3 & $\geq 1$ e $\leq 2$ salários & 138 & 46.0 \\
\hline 25 a 34 anos & 13 & 4.3 & $>2$ e $\leq 4$ salários & 36 & 12.0 \\
\hline 35 a 49 anos & 14 & 4.7 & > 4 salários & 4 & 1.3 \\
\hline a partir de 50 anos & 11 & 3.7 & & & \\
\hline Total & 300 & 100 & Total & 300 & 100 \\
\hline \multicolumn{3}{|c|}{ Escolaridade } & \multicolumn{3}{|c|}{ Município/Sexo } \\
\hline & Frequência & $\%$ & & Frequência & $\%$ \\
\hline sem instrução & 2 & 0.7 & Porto de Pedras & 146 & 48.7 \\
\hline $1^{\circ} \mathrm{grau}$ incompleto & 44 & 14.7 & $\begin{array}{l}\text { S. M. } \quad \text { dos } \\
\text { Milagres }\end{array}$ & 123 & 41.0 \\
\hline $1^{\circ}$ grau completo & 4 & 1.3 & Outros & 31 & 10.3 \\
\hline $2^{\circ}$ grau incompleto & 192 & 64.0 & Total & 300 & 100 \\
\hline $2^{\circ}$ grau completo & 25 & 8.3 & & & \\
\hline superior incompleto & 11 & 3.7 & Feminino & 172 & 57.3 \\
\hline superior completo & 22 & 7.3 & Masculino & 128 & 42.7 \\
\hline Total & 300 & 100 & Total & 300 & 100 \\
\hline
\end{tabular}


Na Figura 1, observa-se a média do ICA em relação ao perfil dos entrevistados. As menores médias do ICA foram encontradas entre as crianças (até 14 anos) e os jovens (15 a 24 anos), com valores abaixo da média geral $(3,04)$. As demais faixas etárias apresentaram valores acima da média geral, sendo que a maior média $(3,41)$ foi encontrada nos entrevistados com idade entre 35 a 49 anos (Figura 1a).

Quanto ao grau de escolaridade (Figura 1b), de uma forma geral notase uma escala crescente, demostrando que quanto maior o grau de instrução maior o ICA. No entanto, mais de $90 \%$ dos entrevistados não possuem ensino superior. Partindo do princípio de que quanto mais alto o nível de escolaridade, mais se tem a capacidade de entender, de se conscientizar e consequentemente maior preocupação com as questões ambientais, a necessidade da educação superior em maior escala é de fundamental importância.

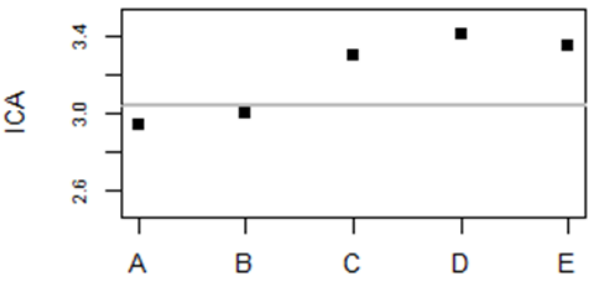

(a)

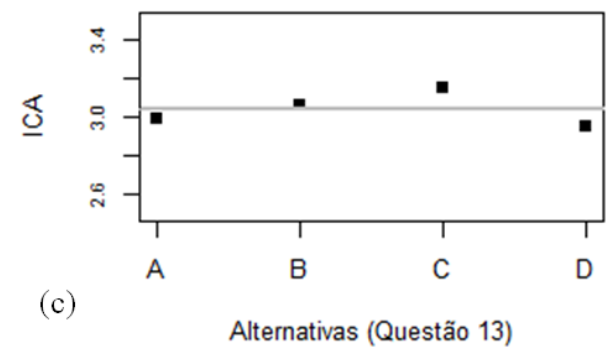

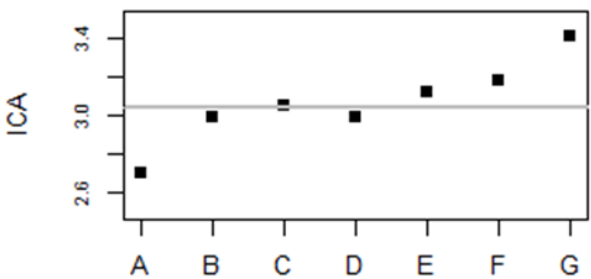

(b)

Alternativas (Questão 12)

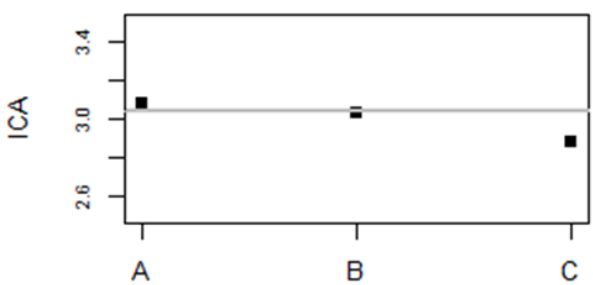

Alternativas (Questão 14)

Figura 1: Média do ICA de acordo com o perfil dos entrevistados. (a) Questão 11: A - até 14 anos, B - 15 a 24 anos, C - 25 a 34 anos, D - 35 a 49, E - a partir de 50 anos. (b) Questão 12: A - sem instrução, $B-1^{\circ}$ grau incompleto, C - $1^{\circ}$ grau completo, D - $2^{\circ}$ grau incompleto, E - $2^{\circ}$ grau completo, F - superior incompleto, G - superior completo. (c) Questão 13: A - menos de um salário, B - um até dois salários, $C$ - mais de dois até quatro salários, D - mais de quatro salários. (d) Questão 14: A - Porto de Pedras, B - São Miguel dos Milagres, C - Outros. A linha contínua em escala de cinza representa a média do ICA de todos os entrevistados.

$\mathrm{Na}$ média do ICA em relação a renda mensal familiar (Figura 1c), podemos observar que os entrevistados com menos de um salário e mais de quatro salários apresentaram médias menores que a média geral, não apresentado uma indicação clara de melhor conscientização ambiental com menor ou maior renda.

Em relação aos municípios (Figura 1d), nota-se que Porto de Pedras e São Miguel dos Milagres encontram-se na média do ICA com valores 
aproximados entre si. Enquanto a média dos outros municípios está abaixo da média geral. Este resultado pode estar relacionado as atividades de Educação Ambiental (EA) realizadas em São Miguel dos Milagres e Porto de Pedras.

A média geral $(3,04)$ do ICA de todos os entrevistados, representada pela linha contínua em escala de cinza na Figura 1, indica potenciais traços de consciência ambiental (Tabela 1). As classificações do ICA de acordo com o perfil dos entrevistados são representadas nas próximas figuras.

De acordo com a idade dos entrevistados, os que apresentaram valores abaixo da média geral (até 14 anos e de 15 a 24 anos), observados na Figura 1a, foram os que apresentaram maiores porcentagens com poucos traços de consciência ambiental (Figura 2). As maiores porcentagens para a classificação consciente em relação ao meio, foram observadas nas faixas etárias de 35 a 49 e a partir de 50 anos, onde foram encontradas as maiores médias do ICA (Figura 1a).

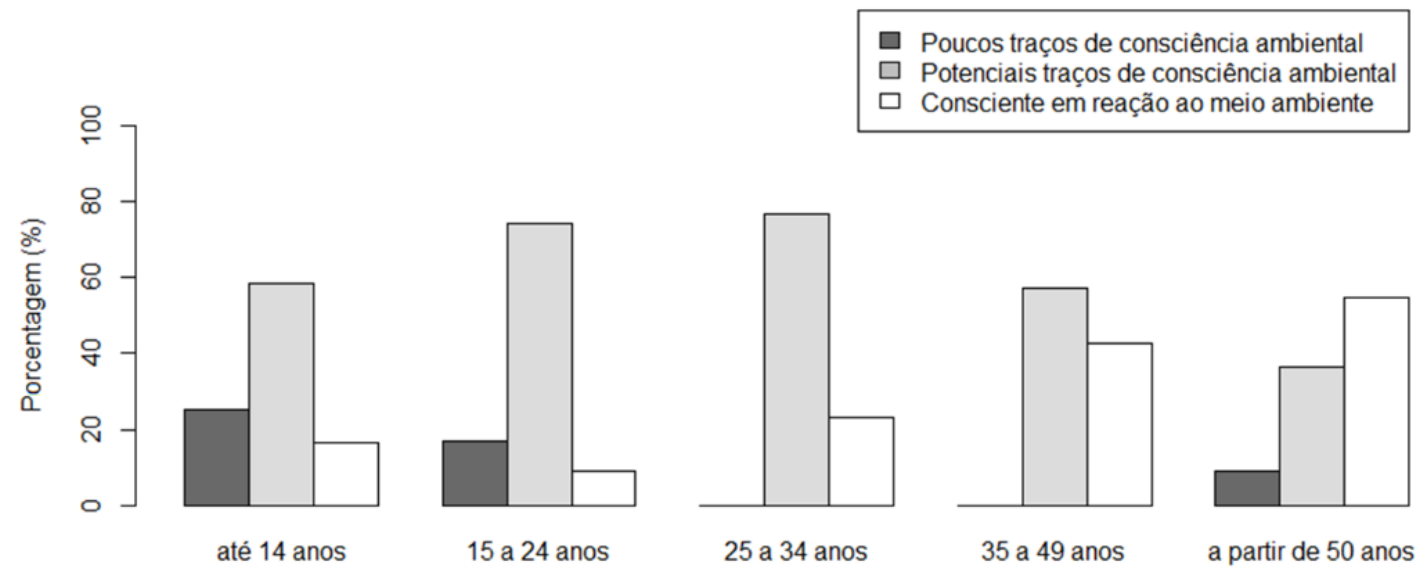

Figura 2: Classificação do ICA de acordo com a idade dos entrevistados.

Os resultados encontrados na Figura 3, faz-se perceber que apesar da maior escolaridade gerar um maior senso crítico, este não leva necessariamente a uma maior conscientização ambiental. Os melhores resultados foram encontrados nos entrevistados com superior completo, onde metade (50\%) apresentaram índices sugerindo ser consciente em relação ao meio ambiente. No entanto, observa-se na Figura 3, que nos demais graus de escolaridade os resultados não indicam uma relação clara de maior conscientização ambiental com maior escolaridade, apesar de ter apresentado ICA com médias sugerindo que quanto maior o grau de instrução maior o ICA (Figura 1b). 


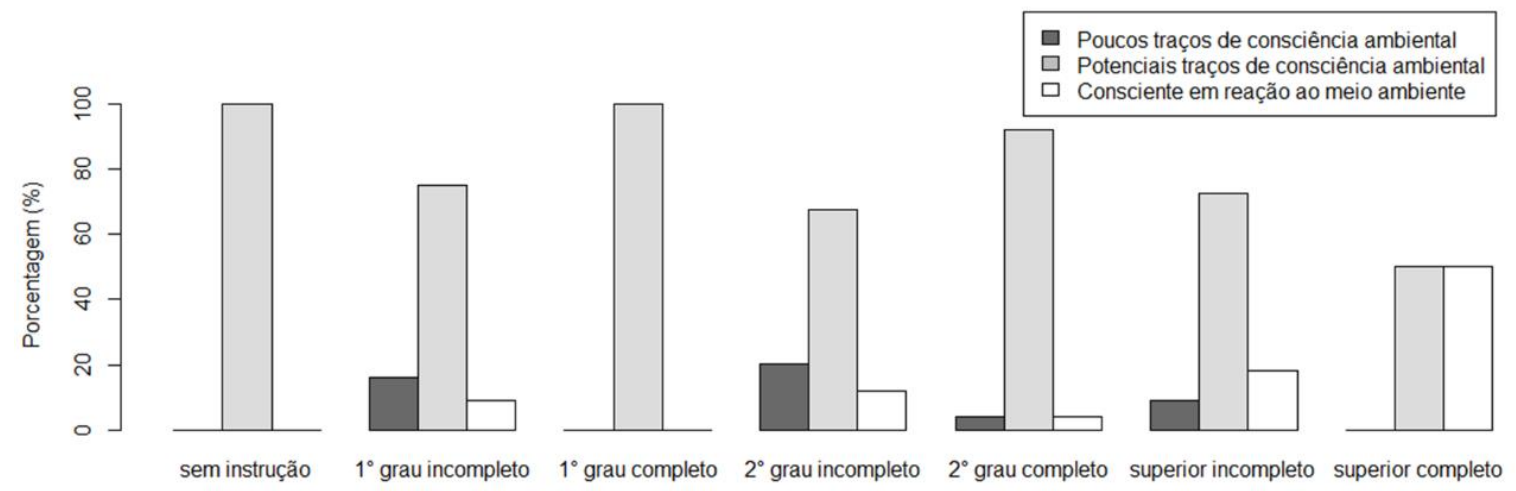

Figura 3: Classificação do ICA de acordo com o grau de escolaridade dos entrevistados.

Mais da metade (64\%) dos entrevistados possuem segundo grau incompleto, e desses, podemos observar na Figura 3, que a maior parte (67.7\%) apresentaram ICA indicando potenciais trações de consciência ambiental, e apenas $12 \%$ indicaram ser consciente em relação ao meio ambiente.

$\mathrm{Na}$ classificação do ICA de acordo com a renda mensal familiar (Figura 4), nota-se que a porcentagem correspondente a ser consciente em relação ao meio ambiente, foi maior nos entrevistados com mais de dois até quatro salários e com mais de quatro salários. No entanto, a maior porcentagem indicando não possuir consciência ambiental, também foi encontrado nas pessoas com mais de quatro salários. Por isso, na média do ICA (Figura $1 \mathrm{c}$ ), os entrevistados com mais de quatro salários apresentaram médias menores que a média geral.
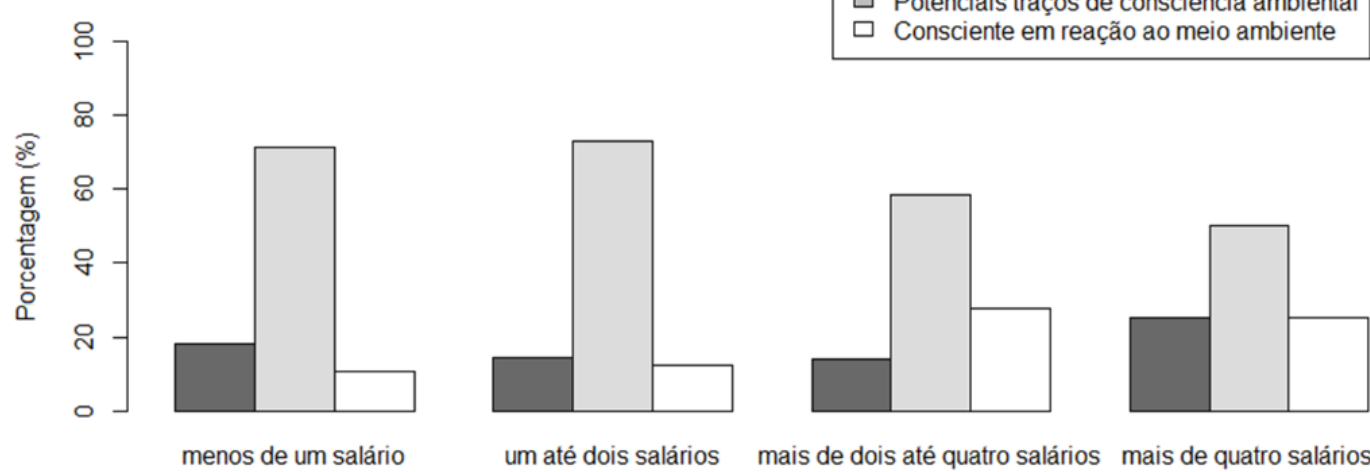

um até dois salários

mais de dois até quatro salários mais de quatro salários

Figura 4: Classificação do ICA de acordo com a renda mensal familiar dos entrevistados.

Na Figura 5, observa-se a classificação por município. Os resultados encontrados em Porto de Pedras e São Miguel dos Milagres foram semelhantes. Em concordância com o observado na Figura 1d, observa-se que a maior porcentagem de poucos traços de consciência ambiental foi encontrada nos entrevistados de outros municípios. No entanto, a quantidade

Revbea, São Paulo, V.11, № 2: 118-126, 2016. 
de entrevistados dos outros municípios foi pequena, sendo assim, seria necessário realizar entrevistas nesses municípios, para confirmar esse resultado.

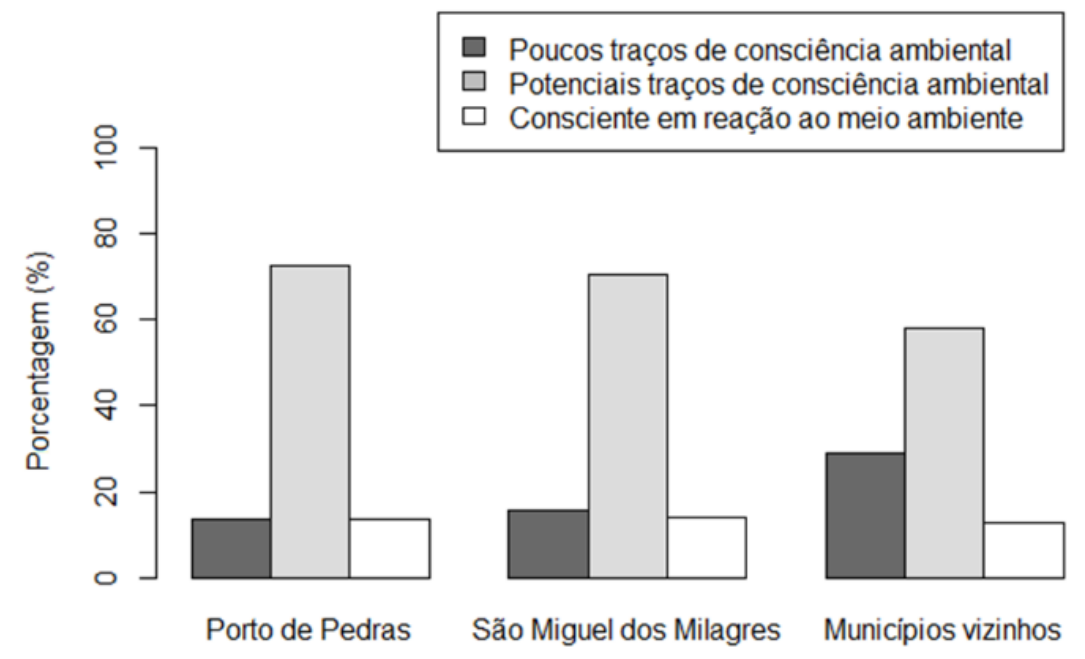

Figura 5: Classificação do ICA de acordo com o município que os entrevistados residem.

A lei 9.795, de 27 de Abril de 1999, artigo 11ํㅡ, parágrafo único, estabelece que "[...] os professores em atividade devem receber formação complementar em suas áreas de atuação, com o propósito de atender adequadamente ao cumprimento dos princípios e objetivos da Política Nacional de Educação Ambiental". Entretanto os resultados obtidos neste estudo deixam claro que a aplicação desta, está muito aquém do que é estabelecido.

\section{Conclusões}

Com o objetivo de identificar e mensurar o grau de conscientização ambiental da população na área central da APA Costa dos Corais, foram aplicados questionários nas principais escolas dos municípios de Porto de Pedras e São Miguel dos Milagres, colônia de pescadores Z-25, ONG's, Projeto Jovens Protagonista da Costa dos Corais e população em geral.

De acordo com os resultados obtidos é perceptível que há traços de consciência ambiental nos entrevistados de Porto de Pedras e São Miguel dos Milagres. A maior porcentagem de poucos traços de consciência ambiental foi encontrada nos entrevistados de outros municípios. No entanto, devido a pequena quantidade de entrevistados residente em outros municípios, seria necessário a realização de entrevistas nos demais munícios da APA, para confirmar esse resultado.

Quanto a escolaridade, os melhores resultados foram encontrados nos entrevistados com maior grau de instrução, porém não indica necessariamente que maior escolaridade leva a uma maior conscientização ambiental. A renda familiar, também não apresentou uma relação clara de melhor conscientização ambiental com menor ou maior renda. Com relação a idade, os piores 
resultados foram encontrados nas crianças e jovens, mostrando a necessidade de incentivar diariamente reflexões e práticas que levem todos, principalmente as crianças, a compreender as questões ambientais, para que se possam formar cidadãos com consciência ambiental.

Portanto, ainda se faz necessário nesses municípios uma EA crítica e emancipatória, que trabalhe a autonomia dos sujeitos, que faça-o refletir sobre a sua condição de gerador e de vítima do problema ambiental na comunidade e no município. Tendo em vista que a EA não se restringe apenas ao ambiental, é preciso que ela almeje mudanças sociais e estruturais nestas comunidades. Sendo assim, uma EA com responsabilidade social.

\section{Referências}

BACKER, P. Gestão ambiental: a administração verde. Rio de Janeiro: Qualitymark, 1995.

BERTOLLINI, G. R. F e POSSAMAI, O. Proposta de Instrumento de Mensuração do Grau de Consciência Ambiental, dos Consumos Ecológicos e dos Critérios de Compra dos Consumidores. Revista de Ciência \& Tecnologia, Vol. 3, n.25/26, p. 17-25, 2006.

BUTZKE, I.C. et al., Sugestão de indicadores para avaliação do desempenho das atividades educativas do sistema de gestão ambiental - SGA da Universidade Regional de Blumenau - FURB. Revista Eletrônica do Mestrado em Educação Ambiental. Vol. Esp. abr./maio/jun.-2001.

CAPELINI, M. Potencialidade e aplicação da prevenção de resíduos de embalagens: abordagem sobre o projeto do produto e o consumo. 2007.273f. Tese (Doutorado) - Escola de Engenharia de São Carlos, Universidade de São Paulo, São Carlos.

CONSELHO NACIONAL DO MEIO AMBIENTE - CONAMA. Resolução CONAMA no 274, de 29 de novembro de 2000. Disponível em: http://www.mma.gov.br/port/conama/legiabre.cfm?codlegi=272. Acesso em maio de 2014.

INSTITUTO DO MEIO AMBIENTE - IMA. Balneabilidade. Disponível em: http://www.ima.al.gov.br/servicos/balneabilidade. Acesso em maio de 2014.

MARQUES, R. M. Estudo de conscientização e práticas ambientais dos estudantes de pós graduação na área de meio ambiente no rio de janeiro. Anais do VI Congresso Nacional de Excelência em Gestão, 2010.

SORRENTINO, M. De Tbilisi a Tessaloniki, a educação ambiental no Brasil. In: JACOBI, P. et al. (orgs.). Educação, meio ambiente e cidadania: reflexões e experiências. São Paulo: SMA. p.27-32. 1998.

ZACCARI, K; OLIVEIRA, V. G. 2013. Avaliando a conscientização ambiental dos estudantes da UNICAMP e a colaboração da disciplina be310. Revista Ciência do Ambiente On-Line. Vol. 9, n. 2, 2013.

Revbea, São Paulo, V.11, № 2: 118-126, 2016. 